\title{
Two new species of the genus Coomansinema Ahmad and Jairajpuri, 1989 (Nematoda: Dorylaimida) with a key to its species
}

\author{
W. AHMAD*, P. MUSHTAQ, SHAHNAZ, S. KUMAR
}

Nematode Biodiversity Research Laboratory, Department of Zoology, Aligarh Muslim University, Aligarh - 202002 INDIA, *E-mail: ahmadwasim57@gmail.com

\section{Article info}

Received October 14, 2018 Accepted December 13, 2018

\begin{abstract}
Summary
Two new species of the genus Coomansinema Ahmad and Jairajpuri, 1989 are described and illustrated. $C$. japonicum $n$. sp. is characterized by having medium size body $(\mathrm{L}=1.40-1.45 \mathrm{~mm})$; lip region truncate with completely amalgamated lips; amphideal fovea goblet - shaped; 16 - $20 \mu \mathrm{m}$ long odontostyle; 23 - $25 \mu \mathrm{m}$ long odontophore; comparatively anterior position of the second pair of pharyngeal glands; amphidelphic female genital system; longitudinal vulva; males with $48-54 \mu \mathrm{m}$ long spicules; 7 - 8 spaced ventromedian supplements and tail long filiform in female and short conoid in male. $C$. longicaudatum $\mathrm{n}$. $\mathrm{sp}$. is characterized by having medium size body $(\mathrm{L}=1.1-1.3 \mathrm{~mm})$; lip region truncate, continuous with completely amalgamated lips; amphideal fovea cup - shaped; 16 - $17 \mu \mathrm{m}$ long odontostyle; 19 - $20 \mu \mathrm{m}$ long odontophore; comparatively anterior position of the second pair of pharyngeal glands; amphidelphic female genital system; transverse vulva, intestinal - prerectum junction with a tongue - like structure and 210 - $269 \mu \mathrm{m}$ long filiform tail. A key to its seven valid species is provided.
\end{abstract}

Keywords: Coomansinema; description; Japan; key to species; new species

\section{Introduction}

Ahmad and Jairajpuri (1989) established the genus Coomansinema and designated $C$. dimorphicauda as its type species reported from India. They differentiated the new genus on the basis of amalgamated, truncate and continuous lip region, without labial or post-labial sclerotization, odontostyle massive, slightly sinuate with thickened tip and wide lumen, anterior position of the second pair of pharyngeal glands and with sexual dimorphism in tail shape, female tail cupola-shaped with slightly dorsally bent terminal process and males with conoid-rounded without any process. Though Coomansinema lacks any labial sclerotization, but due to the position of its second pair of ventrosublateral pharyngeal gland nuclei and their orifices, this genus was placed under Thornenematinae Siddiqi, 1969. Recently, Coomansinema has been studied by Andrássy (2012) who accepted its position among the genera of the family Thornenematidae. Ahmad (1993) added a new species, C. oryzae with transverse vulva from paddy fields in India. Dhanam and Jairajpuri (2002) added two more species C. alduri and C. digiticauda from India, whereas, Ahmad and Shaheen (2004) further described a new species $C$. brevicauda with spike-like tail from Costa Rica, quite different from the other known species of Coomansinema. Andrássy (2012) reported a new species C. taiwanense from Taiwan with longest odontostyle and lower number of ventromedian supplements and discussed in detail the taxonomic position of the genus Coomansinema. Vinciguerra et al., (2014) described new species C. istvani from forest in Ecuador. Khan (1995), while redescribing Timminema pakistanicum, synonymized Coomansinema with Timminema without giving any valid ground of justification. Andrássy (2012) did not accept this

\footnotetext{
$\overline{\text { * }- \text { corresponding author }}$
} 
synonymy. We fully agree with Andrássy's views and consider Coomansinema distinctly different from Timminema.

In the present paper two new species of this genus collected from Japan are described and illustrated. A key to species is also provided.

\section{Materials and Methods}

Soil samples were processed using Cobb's (1918) sieving and decantation and modified Baermann's funnel techniques. The nematodes were extracted and fixed in hot formalin-glycerol fixative, dehydrated by the slow evaporation method (Seinhorst 1959), and mounted in anhydrous glycerin. Permanent mounts were prepared using the paraffin wax ring method (de Maeseneer \& d'Herde 1963). The measurements were taken with an ocular micrometer and drawings made using a drawing tube. Some of the best preserved specimens were photographed using a Nikon Eclipse 80i microscope and a Nikon DS digital camera. Raw photographs were edited using Adobe® Photoshop®.

\section{Results}

\section{Coomansinema japonicum n. sp.}

\section{(Figs. 1\& 2)}

\section{Measurements: See Table 1}

Description: Adult: Moderately slender nematodes of medium size, 1.40 - $1.45 \mathrm{~mm}$ long. Body cylindrical, slightly curved ventrad upon fixation, tapering towards both ends but more so towards the posterior end because of the tapering long filiform tail. Cuticle three-layered, especially distinguishable at caudal region, a thinner outer layer bearing very fine transverse striations through the entire body, thicker intermediate layer with radial striations and thin inner layer; thickness $2 \mu \mathrm{m}$ at anterior region and mid body, and $3-5 \mu \mathrm{m}$ on tail. Lateral chord $6-10 \mu \mathrm{m}$ wide at mid body, occupying about one-eighth to one-fifth (12-18\%) of mid-body diameter. Lip region truncate, continuous with body, $2.4-3.0$ times as wide as high and about one-fourth $(21-27 \%$ ) of body diameter at neck base; lips amalgamated; labial papillae not interfering with labial contour. Amphid fovea goblet-shaped, its aperture occupying about half of lip region diameter. Guiding ring simple, single, at 0.7 - 1.0 times lip region diameter from anterior end. Odontostyle cylindroid, rather robust, with distinctly thickened tip, $1.4-$ 1.5 times the lip region diameter long, its aperture about one-third of its length, ventral arm slightly bent near middle giving a rather sinute appearance. Odontophore linear, rod-like, 1.0 - 1.5 times the odontostyle length. Pharyngeal expansion gradual; expanded portion 5.6 - 6.8 times as long as wide, $2.6-3.2$ times as long as body diameter, and occupying about $45-50 \%$ of total neck length. Nerve ring at $30-40 \%$ of neck length from anterior end. Pharyngeal gland nuclei located as follows: $\mathrm{D}=62-63 \%$; AS1 = $16-17 \%$; AS2 = $19-21 \%$; PS1 = $51-52 \% ;$ PS2 $=52-54 \%$ as per Andrássy (1998); D0 = $53-59 \%$; DN $=56-61 \%$; DO - DN
$=2.3-4.5 \%$; S1N1 = $62-66 \%$; S1N2 = $69-77 \%$; S2N = $82-$ $84 \%$; S2O = $84-85 \%$ as per Loof and Coomans (1970). Cardia rounded conoid, gradually tapering to a fine pointed tip.

Female: Genital system didelphic-amphidelphic, both sexual branches almost equally developed, anterior $173-205 \mu \mathrm{m}$ long or $11-13 \%$ of body length and the posterior $195-255 \mu \mathrm{m}$ long or $13-17 \%$ of body length. Ovaries large sized, usually surpassing the sphincter level, the anterior measuring $44-144 \mu \mathrm{m}$ and posterior 90 - $170 \mu \mathrm{m}$ long; oocytes arranged first in two or more rows, then in a single row. Oviducts consisting a slender proximal part with traces of sperms, measuring $110 \mu \mathrm{m}$ or 2.1 (anterior) and $90 \mu \mathrm{m}$ or 1.7 (posterior) times the corresponding body diameter long; oviduct-uterus junction marked by a sphincter; uterus a short, simple, tube-like structure filled with sperms, measuring $97 \mu \mathrm{m}$ or 1.8 (anterior) and $110 \mu \mathrm{m}$ or 2.1 (posterior) times the corresponding body diameter long ( $n=1$, all the other females being gravid). Vagina extending inwards, $22-26 \mu \mathrm{m}$ or about two-fifths to half of the corresponding body diameter; pars proximalis vaginae 12 $14 \times 6-8 \mu \mathrm{m}$, with somewhat sigmoid walls and surrounded by weak musculature; pars refringens vaginae well developed with two triangular pieces with rounded edges, $7-8 \times 4-5 \mu \mathrm{m}$, their combined width 14-15 $\mu \mathrm{m}$ and a third pentagon-shaped intermediate piece; pars distalis vaginae well developed, $4-5 \mu \mathrm{m}$ long. Vulva a pre-equatorial longitudinal slit. Prerectum $2.1-3.5$, rectum $1.5-1.8$ anal body diam. long. Tail $8-11$ anal body diam. long, tapering gradually behind anus into long filiform tail, terminus in some specimens dorsally bent otherwise ventrally; hyaline part $23-26 \%$ of total tail length. Caudal pores two pairs, one lateral, another sub-dorsal.

Male: Slender nematodes of medium size, $1.12-1.33 \mathrm{~mm}$. Genital system diorchic, with opposed testes. In addition to the ad-cloacal pair, situated at $6-7 \mu \mathrm{m}$ from cloacal aperture, a series $7-8$ regularly spaced ventromedian supplements starting at a distance of $45-51 \mu \mathrm{m}$ from the ad-cloacal pair, each ventromedian $12-13$ $\mu \mathrm{m}$ apart. Spicules total length $48-54 \mu \mathrm{m}$ along the arc, $1.2-1.3$ times that at the chord, 5.0 times the maximum width and 1.8 2.1 times the body diam. at the cloacal aperture. Curvature 126 $-139^{\circ}$. Dorsal contour regularly convex, ventral contour bearing prominent hump and hollow, the former located at $28-33 \%$ of spicule total length from its anterior end. Head well developed, occupying $21-24 \%$ of total length, its dorsal contour conspicuously curved and longer than the ventral. Median piece $10-12$ times as long as wide, occupying $30 \%$ of spicules maximum width, reaching spicule terminal tip. Posterior end $3-4 \mu \mathrm{m}$ wide. Lateral guiding pieces, 8.6 - 10 times as long as wide and about one-fourth of spicules length. Tail convex conoid with broadly rounded terminus. Caudal pores two on each side.

Type habitat and locality: Soil collected from natural forest, Yaku town, Yakushima Island, Japan; 30¹8'15" N 130³4'33.2" E collected by Dr. Mizukubo of National Agricultural Research Center, Tsukuba, Japan. 

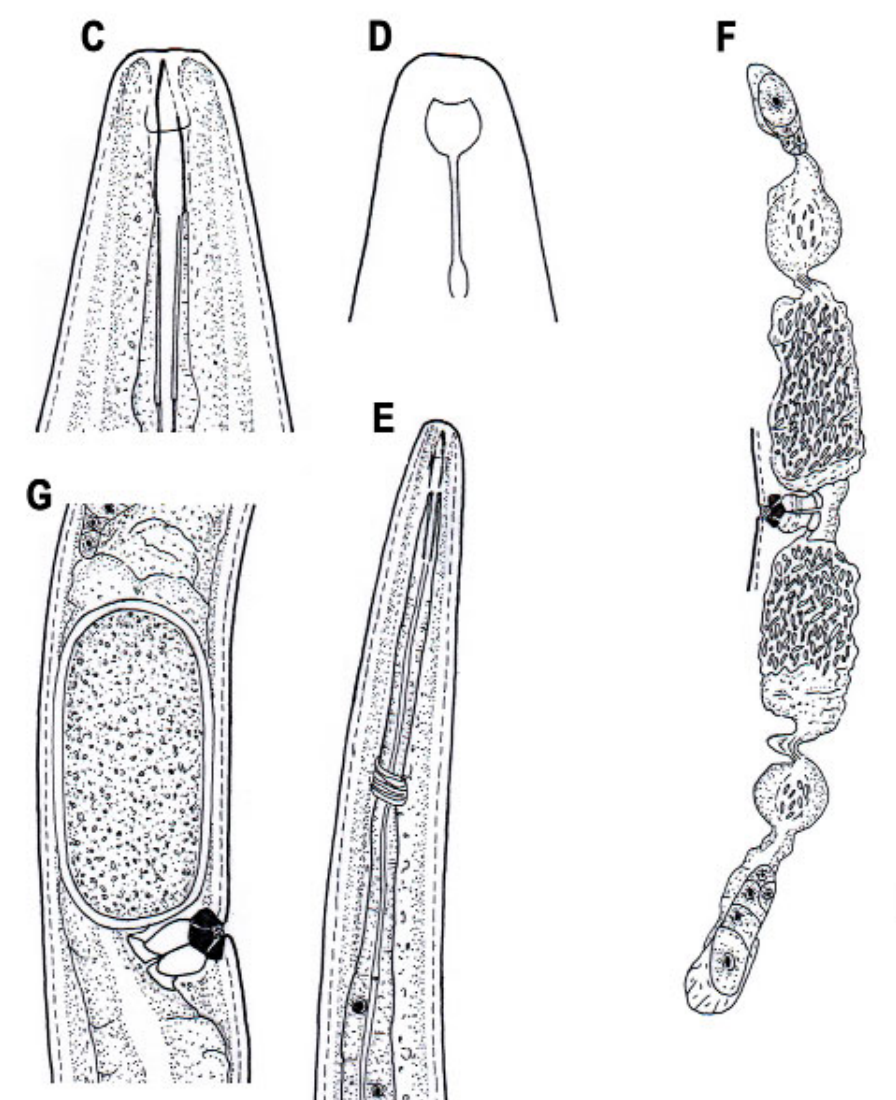

H
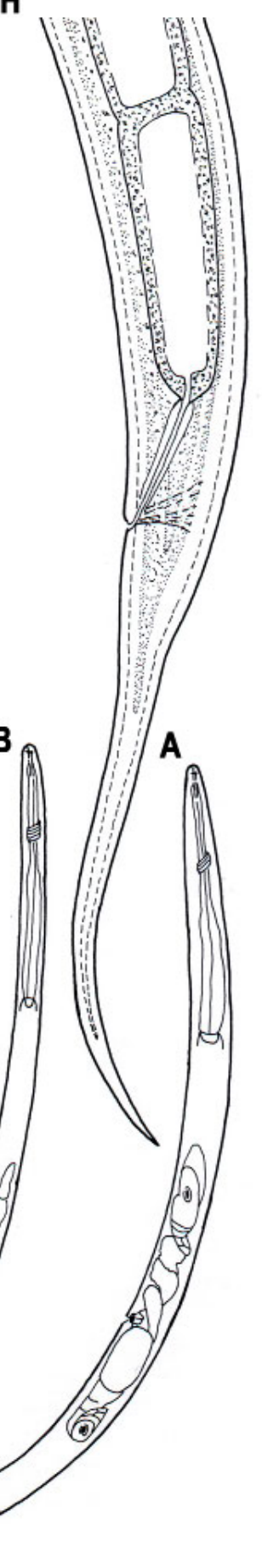

Fig.1. Coomansinema japonicum n. sp. (A) Entire female; (B) entire male; (C) anterior region; (D) anterior end showing amphid; (E) pharyngeal region; (F) female genital system; (G) vulval region with egg; $(\mathrm{H})$ female posterior region; (I) male posterior region. 


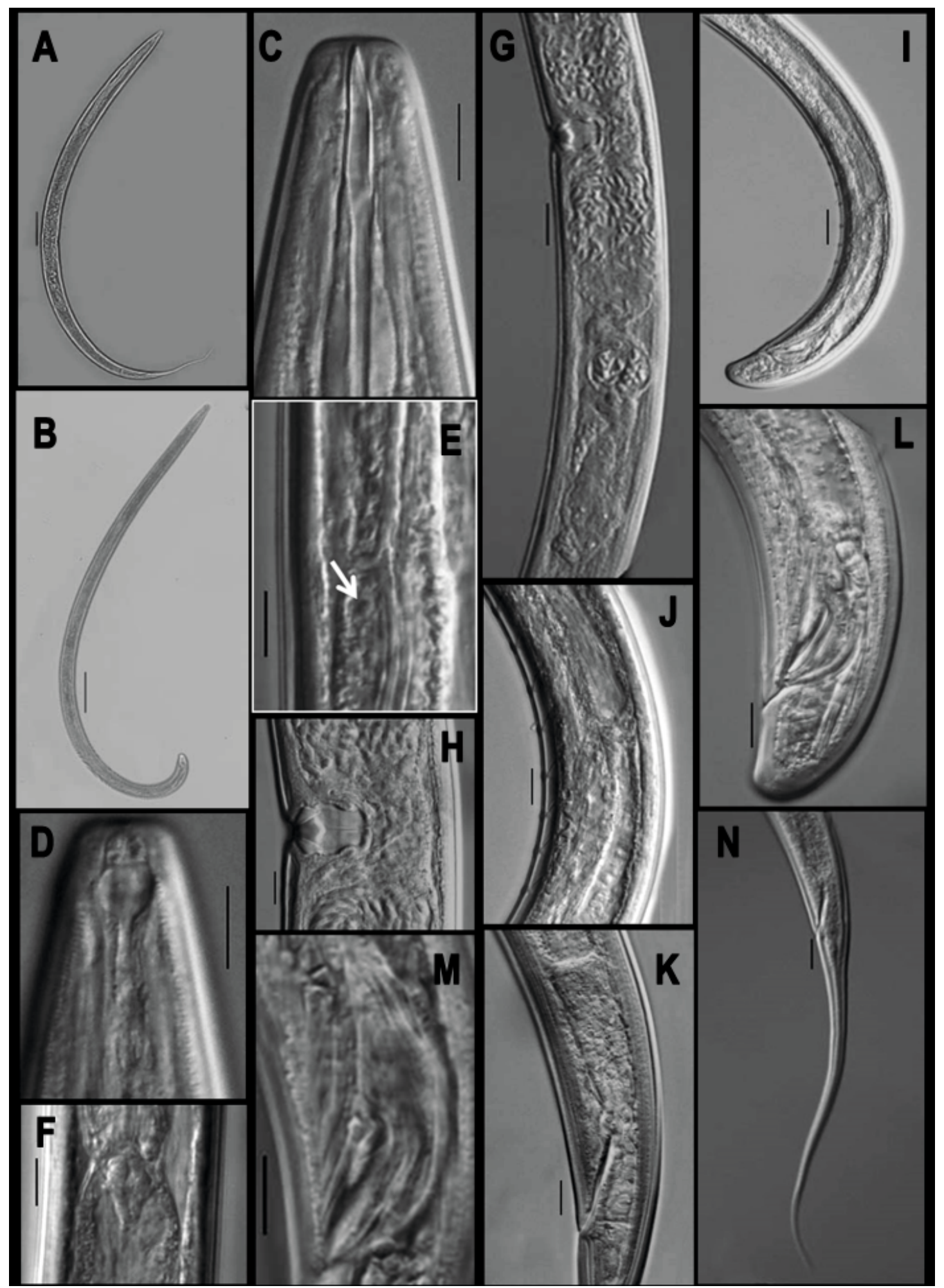

Fig.2. Coomansinema japonicum n. sp. (A) Entire female; (B) entire male; (C) anterior region; (D) anterior end showing amphid; (E) pharyngeal expansion arrow head pointing towards dorsal gland nuclei; $(F)$ pharyngo-intestinal junction; $(\mathrm{G})$ female genital branch (posterior); (H) vulval region; (I) male posterior region; (J) ventromedian supplements; (K) posterior region showing prerectum; (L) male caudal region; (M) male spicules; (N) female caudal region. (Scale bars: A, B = $100 \mu \mathrm{m} ; \mathrm{C}, \mathrm{D}, \mathrm{E}, \mathrm{F}, \mathrm{H}, \mathrm{K}$, $J, L, M=10 \mu \mathrm{m} ; \mathrm{G}, \mathrm{I}, \mathrm{N}=20 \mu \mathrm{m})$ 
Table 1. Measurements of Coomansinema japonicum n. sp.

(All measurements in $\mu \mathrm{m}$ except $\mathrm{L}$ in $\mathrm{mm}$ )

\begin{tabular}{|c|c|c|c|}
\hline Characters & Holotype female & Paratype females & Paratype males \\
\hline$n$ & 1 & 4 & 3 \\
\hline L & 1.42 & $1.43 \pm 0.21(1.40-1.45)$ & $1.23 \pm 0.84(1.12-1.33)$ \\
\hline Body diameter at neck base & 53 & $53.5 \pm 3.4(48-57)$ & $38.6 \pm 5.2(34-46)$ \\
\hline Body diameter at mid body & 51 & $53.0 \pm 3.7(47-56)$ & $39.0 \pm 2.4(36-42)$ \\
\hline Body diameter at anus & 21 & $22.7 \pm 0.8(22-24)$ & $26.0 \pm 0.8(25-27)$ \\
\hline a & 28 & $27.2 \pm 1.6(25.7-29.7)$ & $31.8 \pm 0.4(31.3-32.2)$ \\
\hline b & 4.0 & $4.5 \pm 0.2(4.0-4.6)$ & $3.6 \pm 0.1(3.5-3.8)$ \\
\hline c & 6.8 & $6.8 \pm 1.0(6.0-8.5)$ & $56.3 \pm 0.7(55.5-57.1)$ \\
\hline$c^{\prime}$ & 10 & $9.4 \pm 1.1(7.7-10.9)$ & $0.80 \pm 0.0(0.80-0.88)$ \\
\hline V & 49 & $47.6 \pm 1.2(46.0-49.3)$ & - \\
\hline G1 & 13.3 & $13.2 \pm 0.8(11.8-14.2)$ & - \\
\hline G2 & 16.5 & $15.6 \pm 1.6(13.4-17.6)$ & - \\
\hline Lip region diameter & 12 & $12.5 \pm 0.5(12.0-13.0)$ & $12.6 \pm 0.5(12.0-13.0)$ \\
\hline Lip region height & 5 & $4.3 \pm 0.5(4-5)$ & $4.6 \pm 0.5(4-5)$ \\
\hline Amphid aperture & 6 & $6.1 \pm 0.2(6-6.5)$ & $6.3 \pm 0.5(6-7)$ \\
\hline Odontostyle length & 19 & $17.7 \pm 1.5(16-20)$ & $19.3 \pm 0.5(19-20)$ \\
\hline Odontophore length & 23 & $24 \pm 1.0(23-25)$ & $22 \pm 2.2(20-25)$ \\
\hline Guiding ring from anterior end & 12 & $10 \pm 0.0(10-10)$ & $10 \pm 0.0(10-10)$ \\
\hline Nerve ring from anterior end & 127 & $121.7 \pm 2.0(120-125)$ & $124 \pm 2.9(120-127)$ \\
\hline Neck length & 355 & $321.2 \pm 12.5(308-337)$ & $340.6 \pm 16.1(318-354)$ \\
\hline Expanded part of pharynx & 170 & $150.5 \pm 3.6(145-155)$ & $155.3 \pm 8.8(143-163)$ \\
\hline Cardia length & 23 & $15.7 \pm 1.6(13-17)$ & $14 \pm 0.8(13-15)$ \\
\hline Anterior genital length & 189 & $190.2 \pm 11.4(173-205)$ & - \\
\hline Posterior genital length & 235 & $221.2 \pm 23.3(195-255)$ & - \\
\hline Vaginal depth & 26 & $24.5 \pm 1.5(22-26)$ & - \\
\hline Vulva from anterior end & 700 & $684.2 \pm 20.6(665-719)$ & - \\
\hline Prerectum length & 48 & $74.2 \pm 20.6(52-78)$ & $90 \pm 8.2(80-100)$ \\
\hline Rectum length & 38 & $37.7 \pm 1.1(36-39)$ & $43.3 \pm 0.9(42-44)$ \\
\hline Tail length & 210 & $213.7 \pm 26.8(170-240)$ & $22 \pm 1.6(20-24)$ \\
\hline Spicules length & - & - & $50.6 \pm 2.5(48-54)$ \\
\hline Lateral guiding pieces & - & - & $30.3 \pm 3.7(26-35)$ \\
\hline Ventromedian supplements & - & - & $7.6 \pm 0.5(7-8)$ \\
\hline
\end{tabular}


Type specimens: Holotype female and a paratype male on slide Coomansinema japonicum n. sp./1; paratype females and males on slides Coomansinema japonicum n. sp./2-4; deposited in the nematode collection of the Department of Zoology, Aligarh Muslim University, Aligarh.

Etymology: The new species is named Coomansinema japonicum n. sp. because it is recorded from Japan.

Diagnosis and relationships: Coomansinema japonicum n. sp. is characterized by having $1.40-1.45 \mathrm{~mm}$ (female) and $1.12-1.33$ $\mathrm{mm}$ (male) long body; truncate, continuous lip region with completely amalgamated lips; amphid fovea goblet-shaped, guiding ring single, comparatively anterior position of the second pair of pharyngeal glands; amphidelphic female genital system; longitudinal vulva and long filiform tail $170-240 \mu \mathrm{m}$ and males with dorylaimoid spicules 48 - $54 \mu \mathrm{m}$ long; $7-8$ equally spaced ventromedian supplements and short conoid tail with rounded terminus. The new species differs from all the known species of the genus Coomansinema in having long filiform tail. However, in the presence of longitudinal vulva, this new species comes close to $C$. dimorphicauda and $C$. taiwanense, but differs from the former in having large body $(1.4-1.45$ vs $1.25 \mu \mathrm{m})$, shorter odontostyle (16 -20 vs $22 \mu \mathrm{m}$ ) and longer vs shorter digitate tail ( $c=6-8.5$ vs 43; $c^{\prime}=7.7-10.9$ vs 1.0). From latter, it differs in having shorter body $(1.4-1.45$ vs $1.5-1.88 \mathrm{~mm})$ narrow lip region $(12-13$ vs $17-19$ $\mu \mathrm{m})$, shorter odontostyle (16 - 20 vs $26-28 \mu \mathrm{m})$, anterior position of vulva ( $V=46-49.3$ vs $54-60$ ), smaller spicules (48-54 vs 64 $-70 \mu \mathrm{m})$ and long filiform tail $\left(c=6-8.5\right.$ vs $26-41 ; c^{\prime}=7.7-10.9$ vs $1.1-1.7)$. From $C$. brevicauda, it differs by having narrow lip width (12 - 13 vs $15-17 \mu \mathrm{m})$, longitudinal vulva (vs transverse), longer tail (vs tail initially cupola then strongly narrowed to filiform process). From $C$. istvani the new species differs in having shorter odontostyle (16 - 20 vs $20-27 \mu \mathrm{m})$, longitudinal vulva (vs transverse) and longer tail $170-240$ vs $17-31 \mu \mathrm{m}(\mathrm{c}=6-8.5$ vs 35.8 $-68.8 ; c^{\prime}=7.7-10.9$ vs $0.6-1.0$ ).

\section{Coomansinema longicaudatum n. sp.}

(Figs. 3 \& 4)

Measurements: See Table 2

Description: Female: Moderately slender nematodes of medium size, $1.1-1.3 \mathrm{~mm}$ long. Body cylindrical, slightly curved ventrad upon fixation, tapering towards both ends but more so towards the posterior end because of the tapering long filiform tail. Cuticle three-layered, especially distinguishable at caudal region, where it consists of thinner outer layer bearing very fine transverse striations through the entire body, thicker intermediate layer with radial striations and thin inner layer; thickness $1.5-2.0 \mu \mathrm{m}$ in the anterior region, $2.0 \mu \mathrm{m}$ at mid body and $3.0 \mu \mathrm{m}$ on tail. Lateral chords $6-9 \mu \mathrm{m}$ wide at mid body, occupying about one-seventh to one-fifth (15-21\%) of mid body diameter. Lip region rounded, continuous with body, $2.2-2.7$ times as wide as high and about one-third $(28-31 \%)$ of body diameter at neck base; lips amalga- mated. Amphid fovea cup-shaped, its aperture occupying about half to three-fifths $(50-63 \%)$ of lip region diameter. Guiding ring single, at $0.8-1.0$ times lip region diameters from anterior end. Odontostyle cylindroid, rather robust, with distinctly thickened tip, 1.3 - 1.7 times the lip region diameter long, its aperture about one-third of its length, ventral arm slightly bent near middle giving a rather sinute appearance. Odontophore linear, rod-like, 1.1-1.3 times the odontostyle length. Anterior region of pharynx enlarging gradually at $57-60 \%$ of neck length; basal expansion $5.5-6.5$ times as long as wide, $3.1-3.2$ times as long as body diameter, occupying about $40-48 \%$ of neck length. Pharyngeal gland nuclei located as follows: $\mathrm{D}=62-65 \%$; AS1 = $10-12 \%$; AS2 = $16-$ $18 \%$; PS1 = $46-47 \%$; PS2 = $50-53 \%$ as per Andrássy (1998); $\mathrm{DO}=58-62 \%$; DN = $61-63 \%$; DO-DN = $2.4-3.9 \%$; S1N1 = $69-72 \%$; S1N2 = $71-75 \%$; S2N = $81-84 \%$; S2O = $83-85 \%$ as per Loof and Coomans (1970). Nerve ring at $38-40 \%$ of total neck length. Cardia first rounded conoid, then gradually tapering to a fine rounded terminus. Genital system didelphic-amphidelphic; both sexual branches almost equally well developed, anterior 85 - $99 \mu \mathrm{m}$ long or $7-8 \%$ of total body length and the posterior $90-$ $118 \mu \mathrm{m}$ long or $7-9 \%$ of body length. Ovaries small sized, usually not surpassing the sphincter level, measuring anterior $30-43 \mu \mathrm{m}$ and the posterior 40 - $56 \mu \mathrm{m}$ long; oocytes arranged first in two or more rows, then in a single row. Oviducts consisting a slender proximal part and a well developed pars dilatata, measuring 42 - $50 \mu \mathrm{m}$ or $1.0-1.3$ (anterior) and $46-48 \mu \mathrm{m}$ or 1.2-1.7 (posterior) times the corresponding body diameter long. Oviduct-uterus junction marked by a sphincter. Uterus a short, simple, tube-like structure without trace of sperms, measuring $42-52 \mu \mathrm{m}$ or $1.0-$ 1.3 (anterior) and $41-53 \mu \mathrm{m}$ or $1.0-1.2$ (posterior) times the corresponding body diameter long. Vagina extending inwards, about two-fifths to one-half ( $40-50 \%$ ) of corresponding body diameter; pars proximalis vaginae $10-12 \times 6-7 \mu$ m with somewhat sigmoid walls, surrounded by weak musculature; pars refringens vaginae well developed, comma-shaped, $5-6 \times 2-3 \mu \mathrm{m}$, their combined width $11 \times 12 \mu \mathrm{m}$, distal part of both close to each other but their proximal part far apart; pars distalis vaginae well developed, $5-6$ $\mu \mathrm{m}$ long. Vulva a transverse slit. Intestinal-prerectum junction with a well developed conical tongue-like structure. Prerectum 1.2 1.9 , rectum $1.3-1.6$ anal body diam. long. Tail long filiform, $9-11$ anal body diam. long; hyaline part $29-31 \%$ of total tail length. Caudal pore two pairs, one lateral, another sub-dorsal.

Male: Not found.

Type habitat and locality: Tall grasses from Koibuchimachi, Mito C, Ibaraki Prefecture, Japan; 36²0'29"N 140²6'48”E; collected by Dr. Masaki Araki on 07.12. 2011.

Type specimens: Holotype female on slide Coomansinema longicaudatum n. sp. /1; paratype females on slides Coomansinema longicaudatum n. sp. /2-8; deposited with the nematode collection of the Department of Zoology, Aligarh Muslim University, India. Etymology: The new species is named C. longicaudatum n. sp. because of its long tail. 


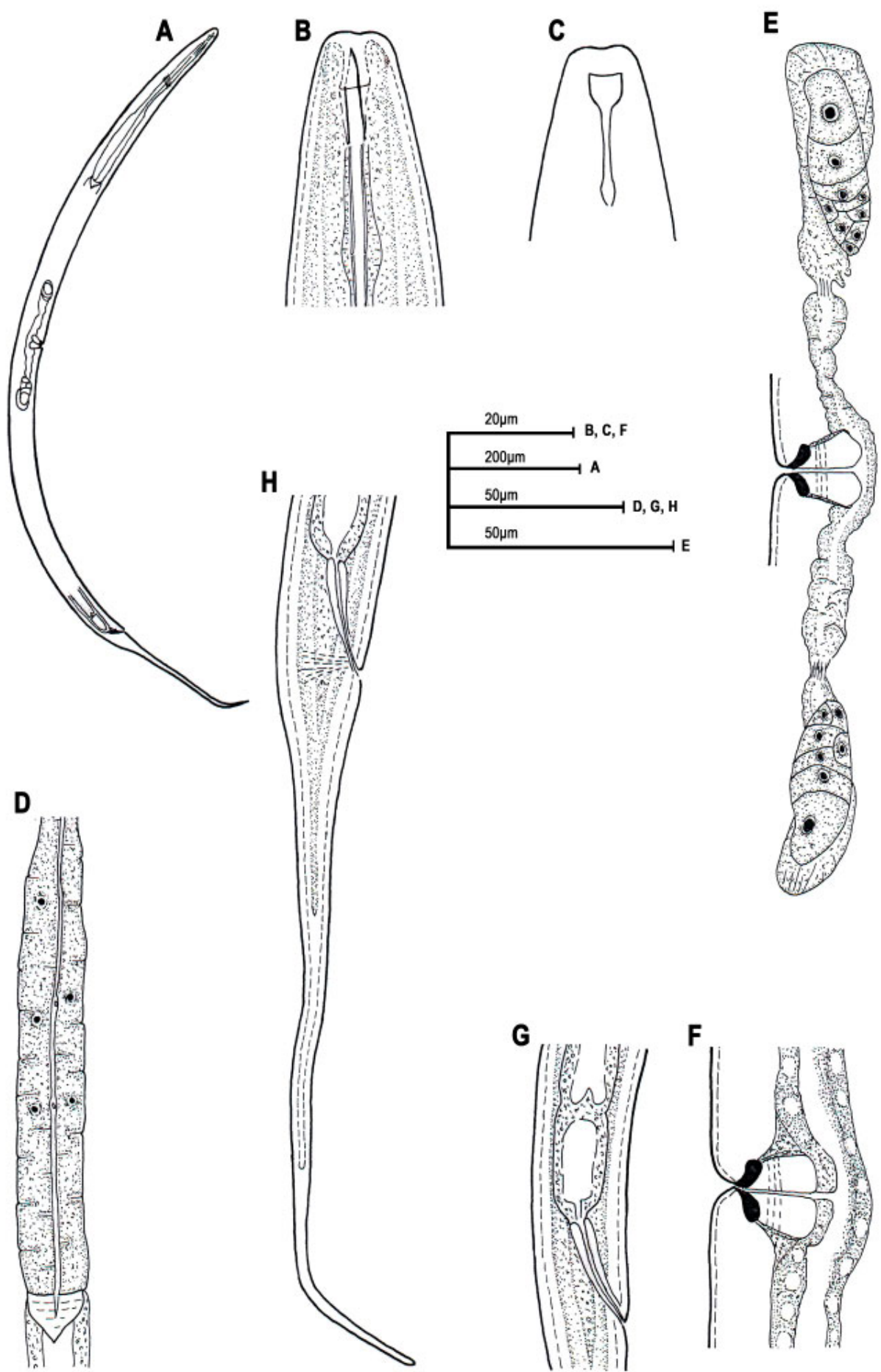

Fig.3. Coomansinema longicaudatum n. sp. (A) Entire female; (B) anterior region; (C) anterior end showing amphid; (D) pharyngeal region; (E) female genital system; $(\mathrm{F})$ vulval region; $(\mathrm{G})$ posterior region showing prerectum; $(\mathrm{H})$ female posterior region. 


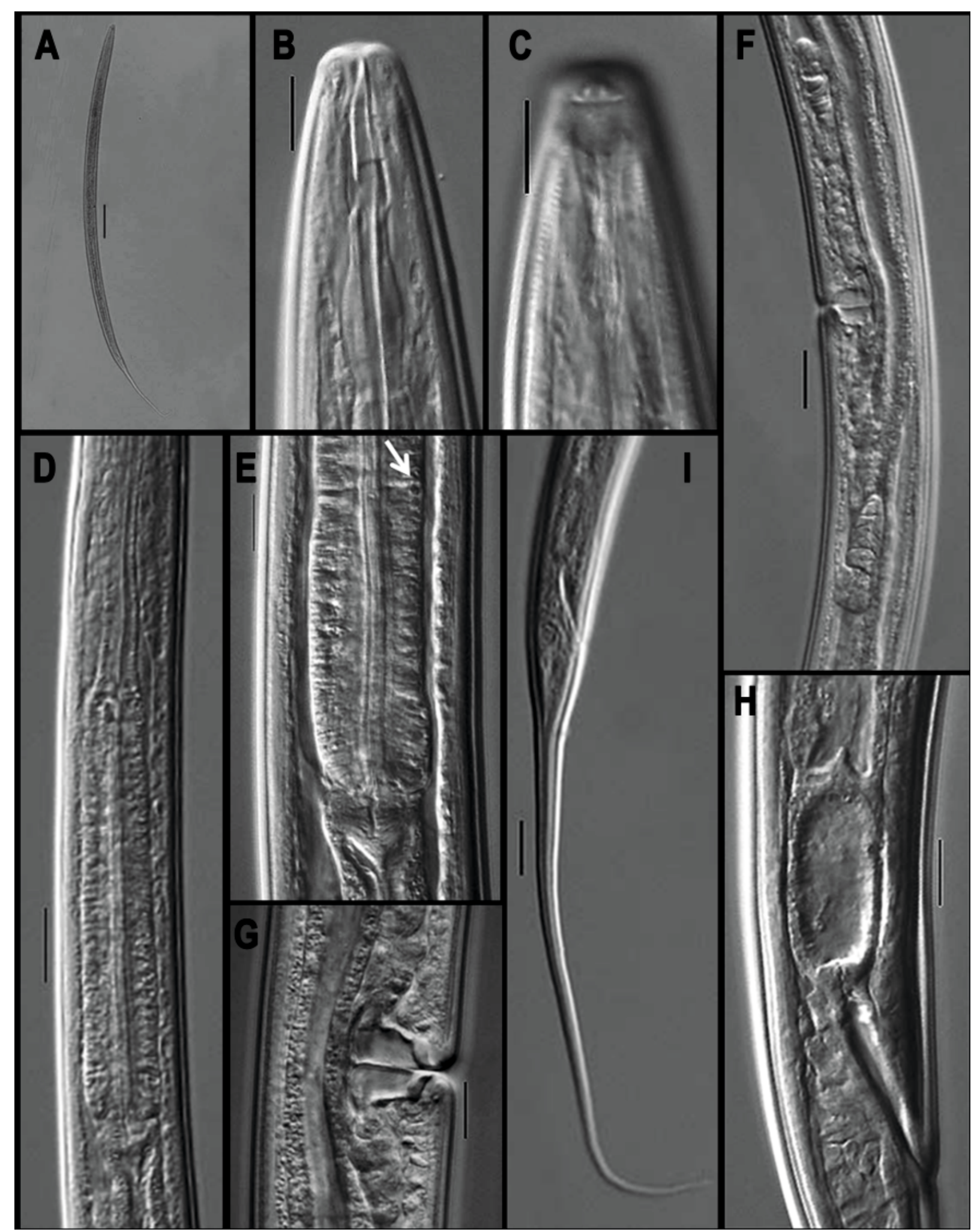

Fig.4. Coomansinema longicaudatum n. sp. (A) Entire female; (B) anterior region; (C) anterior end showing amphid; (D) expanded part of pharynx (E) pharyngeal base showing subventral gland nuclei and pharyngo-intestinal junction (arrow head pointing towards S2N); (F) female genital system; (G) vulval region; (H) posterior region showing prerectum; (I) caudal region. (Scale bars: $A=100 \mu \mathrm{m} ; \mathrm{B}, \mathrm{C}, \mathrm{E}, \mathrm{G}, \mathrm{H}=10 \mu \mathrm{m} ; \mathrm{D}, \mathrm{F}, \mathrm{I}=20 \mu \mathrm{m}$ ). 
Table 2. Measurements of Coomansinema longicaudatum n. sp.

(All measurements in $\mu \mathrm{m}$ except $\mathrm{L}$ in $\mathrm{mm}$ )

\begin{tabular}{|c|c|c|}
\hline Characters & Holotype female & Paratype females \\
\hline$n$ & 1 & 8 \\
\hline L & 1.23 & $1.23 \pm 0.66(1.12-1.35)$ \\
\hline Body diameter at neck base & 39 & $37.9 \pm 1.7(35-40)$ \\
\hline Body diameter at mid body & 40 & $38.9 \pm 1.5(37-41)$ \\
\hline Body diameter at anus & 22 & $22.8 \pm 1.0(21-24)$ \\
\hline a & 33.3 & $31.9 \pm 1.1(29.6-33.4)$ \\
\hline b & 4.1 & $4.3 \pm 0.2(3.9-4.5)$ \\
\hline c & 5.0 & $5.3 \pm 0.2(5.0-5.6)$ \\
\hline$c^{\prime}$ & 11.1 & $10.2 \pm 0.6(9.1-11.2)$ \\
\hline V & 44.2 & $43.8 \pm 1.7(41.8-47.5)$ \\
\hline G1 & 8.0 & $7.6 \pm 0.4(7.1-8.4)$ \\
\hline G2 & 8.7 & $8.4 \pm 0.5(7.5-9.1)$ \\
\hline Lip region diameter & 11 & $11.1 \pm 0.3(11-12)$ \\
\hline Lip region height & 4 & $4.5 \pm 0.5(4-5)$ \\
\hline Amphid aperture & 6 & $6.5 \pm 0.5(6-7)$ \\
\hline Odontostyle length & 16 & $16.9 \pm 0.3(16-17)$ \\
\hline Odontophore length & 20 & $19.6 \pm 0.5(19-20)$ \\
\hline Guiding ring from anterior end & 10 & $9.6 \pm 0.7(9-11)$ \\
\hline Nerve ring from anterior end & 115 & $115.5 \pm 1.7(113-118)$ \\
\hline Neck length & 298 & $290.1 \pm 7.2(283-306)$ \\
\hline Expanded part of pharynx & 122 & $123.1 \pm 2.7(118-127)$ \\
\hline Cardia length & 14 & $15.5 \pm 0.9(14-17)$ \\
\hline Anterior genital length & 99 & $93.1 \pm 4.3(85-99)$ \\
\hline Posterior genital length & 107 & $103.8 \pm 9.1(90-118)$ \\
\hline Vaginal depth & 20 & $17.9 \pm 0.8(17-19)$ \\
\hline Vulva from anterior end & 544 & $541.3 \pm 16.7(507-568)$ \\
\hline Prerectum length & 35 & $35.1 \pm 4.1(30-40)$ \\
\hline Rectum length & 32 & $33.8 \pm 1.6(32-37)$ \\
\hline Tail length & 245 & $232.3 \pm 16.7(210-269)$ \\
\hline
\end{tabular}


Diagnosis and relationships: C. longicaudatum n. sp. is characterized by having $1.1-1.3 \mathrm{~mm}$ long body; lip region truncate, continuous with amalgamated lips; amphideal fovea cup-shaped; 16 - $17 \mu \mathrm{m}$ long odontostyle; 19 - $20 \mu \mathrm{m}$ long odontophore; comparatively anterior position of the second pair of pharyngeal glands; amphidelphic female genital system; transverse vulva; intestinal-prerectum junction with a tongue-like structure and 210 $-269 \mu \mathrm{m}$ long filiform tail.

The new species closely resembles $C$. japonicum n. sp. in having long filiform tail in females but distinctly differs from it in the presence of a transverse vulva (vs longitudinal). It further differs from it in the shape of amphid (cup-shaped vs goblet-shaped), shorter odontostyle (vs odontostyle $16-20 \mu \mathrm{m}$ ), shorter prerectum (vs prerectum $35-108 \mu \mathrm{m}$ ) and in the absence of males (vs presence). Remarks. Ahmad and Jairajpuri (1989) placed the genus Coomansinema in the subfamily Thornenematinae Siddiqi, 1969 mainly because of anterior position of its second pair of ventrosublateral pharyngeal glands and their orifices. In the shape of its lip region, the nature of odontostyle and the position of second pair of subventral pharyngeal glands, Coomansinema closely resembles the genus Opisthodorylaimus Ahmad and Jairajpuri, 1982, except for having didelphic-amphidelphic females. All the Opisthodorylaimus species possess mono-opisthodelphic female genital system. Carbonell and Coomans (1986) while revising the genus Opisthodorylaimus recorded anterior uterine branch from completely absent (O. filicaudatus), mostly reduced to a uterine sac showing different degree of degeneration ( 0 . cavalcantii) to anatomically complete (O. paracavalcantii) but never functional. Although, Gagarin (2004) described O. major, an amphidelphic species from fresh water habitat in Russia, it is quite different from other known species of Opisthodorylaimus and do not fit in the generic diagnosis of Opisthodorylaimus and hence Andrássy (2007) rightly considered it a species incertae sedis. As of today the placement of these two new species seems most justified in the genus Coomansinema rather than Opisthodorylaimus till sequence data on species representing both these genera is not available.

In the presence of long filiform tail, the two new species also resembles the long-tailed dorylaim genera Paradorylaimus Andrássy, 1969 and Laimydorus Siddiqi, 1969. However, they distinctly differs from both in their characteristic wide, massive odontostyle, distinctly thickened at tip, and anterior position of S2N. As regards the tail shape, Coomansinema has a short conoid tail with slight projection at tip in the type species to characteristic elongation after the short conoid portion (cf. C. oryzae, C. brevicauda) and now the two newly described species has long filiform tail. Similar diversity in tail shape is quite common in the genus Mesodorylaimus Andrássy, 1959 and several other dorylaim genera.

Andrássy (2012) doubted the validity of $C$. alduri Dhanam and Jairajpuri, 2002 as the differences from $C$. oryzae reported in original description of $C$. alduri appear to be irrelevant. He also considered the position of C. digiticauda Dhanam and Jairajpuri, 2002 under Coomansinema rather doubtful because of the shape of its lip region being quite different from Coomansinema pattern, less anterior position of the second pair of pharyngeal glands, longer prerectum and a non-offset tail peg. We concur with Andrássy (2012) and the two species C. alduri and C. digiticauda are considered as species inequirendae.

Key to species of genus Coomansinema.

1. Female tail long filiform, usually more than 8 anal body width long.....................................

- Female tail shorter, usually less than 4 anal body width long............................................

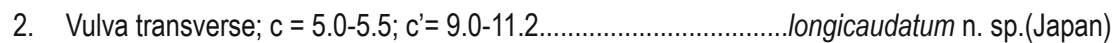

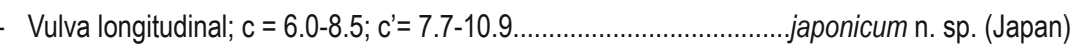

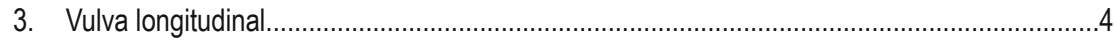

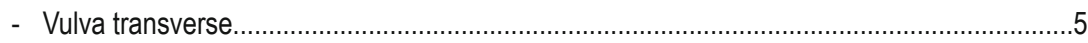

4. Female $1.25 \mathrm{~mm}$ long; odontostyle $22 \mu \mathrm{m}$ long; $c^{\prime}=1.0$; ventromedian supplements in male 12-15.................................................... dimorphicauda Ahmad \& Jairajpuri, 1989 (India)

- Female 1.5-1.8 mm long; odontostyle 26-28 $\mu \mathrm{m}$ long; $c^{\prime}=1.1-1.7$; ventromedian supplements in male 7-8..............................................................taiwanense Andrássy, 2012 (Taiwan)

5. Tail cupola-shaped with a very short finger-like, dorsally bent blunt process, female 0.9-1.5 $\mathrm{mm}$ long; odontostyle 20-27 $\mu \mathrm{m}$ long; c'=0.6-1.0 istvani Vinciguerra, Orselli \& Clausi, 2014 (Ecuador)

- Tail cupola-shaped with a long, narrow, dorsally bent process.. .6

6. Female 1.7-1.9 mm long; $c=17-20 ; c^{\prime}=2.4-3.2$; long tongue like structure present at intestineprerectum junction; ventromedian supplements in male 12-13. ..oryzae Ahmad, 1993 (India, Ecuador, Peru)

- Female 1.3-1.6 mm long; $c=20-39 ; c^{\prime}=1.7-2.2$; tongue like structure absent at intestineprerectum junction; ventromedian supplements in male $10 \ldots$ brevicauda Ahmad and Shaheen, 2004 (Costa Rica, Ecuador, Peru) 


\section{Conflict of Interest}

All authors have no potential conflict of interest pertaining to this submission to Helminthologia.

\section{Acknowledgments}

The authors are thankful to Dr. Mizukubo of National Agricultural Research Center, Tsukuba, Japan for kindly providing some specimens of Coomansinema sp. from his collection. First author is thankful to INSA-JSPS for financial assistance under their exchange programme. Shahnaz and Sumit Kumar are thankful to University Grants Commission Non-NET and Rajiv Gandhi National Fellowship respectively.

\section{References}

AнmAd, W. (1993): Description of Thonus goaensis sp. n. and Coomansinema oryzae sp. n. (Nematoda: Dorylaimida). Afro-Asian Journal of Nematology, 3: 173 - 176

Ahmad, W., JaIRAJPURI, M.S. (1989): Coomansinema n. gen. (Nematoda: Dorylaimida) with the description of $C$. dimorphicauda $\mathrm{n}$. sp. Nematologica 35: 142 - 146. DOI: 10.1163/002825989X00287 Ahmad, W., Shaheen, A. (2004): Five new and two known species of the family Dorylaimidae (Nematoda: Dorylaimida) from Costa Rica. Nematology, 6: 567 - 584. DOI: 10.1163/1568541042665232

ANDRÁSSY, I. (1969): Taxonomische Uebersicht der Familien Prodorylaimidae $\mathrm{n}$. fam. und Dorylaimidae de Man, 1876. Opuscula Zoologica Budapest, 9: 187 - 233

ANDRASSY, I. (1998): Once more: the oesophageal gland nuclei in the dorylaimoid nematodes. Opusc. Zool. Budapest, XXXI: 165 - 171 ANDRASSY, I. (2012): On the genus Coomansinema Ahmad \& Jairaj- puri, 1989 (Dorylaimida: Thornenematidae), with description of one new and two rare species. Journal of Nematode Morphology and Systematics, 15: $87-101$

Совв, N. A. (1918): Estimating the nema population of the soil. Agric. Tech. Circ. Bur.PI. Ind.U.S. Dep. Agric., No., 1 - 48

DE MAN, J.G. (1876): Onderzoekingen over viij in de aarde levende Nematoden. Tijdschrift Nederlandsche Dierkundige Vereenigning, 2: $78-196$

Dhanam, M., JaIRAJPURI, M.S. (2002): Two new species of Coomansinema Ahmad \& Jairajpuri, 1989 (Nematoda: Dorylaimida) from Malnad, Karnataka, India. International Journal of Nematology, 12: $19-22$

De Maeseneer, J., D' Herde, J. (1963): Methodes utilisees pour l'etude des anguillules libres du sol. [Methods used for the study of free-living soil nematodes]. Revue de Agric. Bure., 16: 441 - 447 KHAN, H.A. (1995): Redescription of Timminema pakistanicum Khan and observations on the variability of taxonomic characters. Bangladesh Journal of Zoology, 23: 167 - 172

Loof, P.A.A., Coomans, A. (1970): Morphology and taxonomy of Bathyodontina (Dorylaimida). Nematologica, 16: 180 - 196. DOI: 10.1163/187529270X00199

SIDDIQI, M. R. (1969). Mumtazium mumtazae n. gen, n. sp. (Nematoda : Tylencholaimidae) with the proposal of Laimydorus $\mathrm{n}$. gen. (Thornenematidae). Nematologica, 15: $234-240$

SEINHORST, J. W. (1959): A rapid method for the transfer of nematodes from fixative to anhydrous glycerin. Nematologica, 8: 117 - 128. DOI: 10.1163/187529259X00381

VinciguerRA, M.T., Orselli, L., Clausi, M. (2014): One new and two known species of Aporcelinus Andrássy, 2009 and a new species of Coomansinema Ahmad \& Jairajpuri, 1989 (Nematoda: Dorylaimida). Nematology, 16: 303 - 322. DOI: 10.1163/1568541100002767 